\title{
O uso de expressões artísticas no ensino de Biologia Celular: Uma proposta combinando metodologias ativas e interdisciplinaridade
}

\author{
The use of artistic expressions in Cell Biology teaching: A proposal combining active methodologies \\ and interdisciplinarity
}

El uso de expresiones artísticas en la enseñanza de la Biología Celular: Una propuesta que combina metodologías activas e interdisciplinariedad

\author{
Wallison dos Santos Soares \\ ORCID: https://orcid.org/0000-0003-1392-2445 \\ Instituto Federal de Educação, Ciência e Tecnologia de Brasília, Brasil \\ E-mail: wallison.institucional@gmail.com \\ Mayara Lustosa de Oliveira Barbosa \\ ORCID: https://orcid.org/0000-0003-3356-0998 \\ Instituto Federal de Educação, Ciência e Tecnologia de Brasília, Brasil \\ E-mail: mayara.barbosa@ifb.edu.br \\ Juliana Rocha de Faria Silva \\ ORCID: https://orcid.org/0000-0002-1834-2805 \\ Instituto Federal de Educação, Ciência e Tecnologia de Brasília, Brasil \\ E-mail: juliana.silva@ifb.edu.br
}

\begin{abstract}
Resumo
Neste artigo propõe-se uma estratégia interdisciplinar para o ensino de Biologia Celular no ensino médio a partir do uso de expressões artísticas e das metodologias ativas. Para isso, turmas controle e experimental de alunos do $1^{\circ}$ ano do Ensino Médio da rede pública do Distrito Federal foram selecionadas para receber aulas do conteúdo de Biologia Celular. Na turma controle, o conteúdo foi abordado de maneira expositiva e com a organização dos alunos em seminários - da maneira como já estavam acostumados cotidianamente no contexto escolar das aulas de Biologia. Na turma experimental, houve o trabalho com projetos em grupos com o uso de expressões artísticas e desenvolvimento de produtos educacionais como fruto de suas aprendizagens dos temas relacionados à Biologia Celular. A produção artística incluiu paródias, maquetes, histórias em quadrinhos e desenhos. Um teste avaliativo aplicado em ambos os grupos revelou resultados promissores e estatisticamente significativos para o aprendizado dos alunos da turma experimental em relação à turma controle. Ainda, um questionário respondido por eles permitiu verificar que o uso das expressões artísticas motivou e despertou o interesse, além de envolver e unir todos os alunos em torno da produção.

Palavras-chave: Ensino; Biologia celular; Expressões artísticas; Metodologias ativas; Ensino médio.
\end{abstract}

\begin{abstract}
This paper proposes an interdisciplinary strategy for teaching Cell Biology in high school through using artistic expressions and active methodologies. For this, to receive classes on the content of Cell Biology were selected control and experimental groups of 1st-year high school students from the public high school system of the Distrito Federal. In the control class, the content approach was made in an expositive way, with the organization of the students in seminars. This was a way that they already used in the school context of Biology classes. In the experimental group, there was the work with projects using artistic expressions and the development of educational products as a result of their learning about the themes related to Cell Biology. The art production included parodies, scale models, comics, drawings, and theater. An evaluation test applied to both groups revealed promising and statistically significant results for the student's learning from the experimental class concerning the control class. Furthermore, a questionnaire answered by them allows us to verify that the artistic expressions use motivated and awakened interest and involved and united all the students around the production.
\end{abstract}

Keywords: Teaching; Cell biology; Artistic expressions; Active methodologies; High school.

\section{Resumen}

Este trabajo propone una estrategia interdisciplinar para la enseñanza de la Biología Celular en la escuela secundaria a partir del uso de expresiones artísticas y metodologías activas. Para ello, se seleccionaron clases de control y experimentales de alumnos de $1^{\circ}$ de la escuela secundaria del sistema público del Distrito Federal para recibir clases 
sobre el contenido de Biología Celular. En la clase de control, el contenido se abordó de forma expositiva y con la organización de los alumnos en seminarios, de la forma a la que ya estaban acostumbrados en el contexto escolar de las clases de Biología. En la clase experimental, se trabajó con proyectos grupales con el uso de expresiones artísticas y desarrollo de productos educativos como resultado de su aprendizaje de temas relacionados con la Biología Celular. La producción artística incluía parodias, maquetas, cómics y dibujos. Una prueba de evaluación aplicada a ambos grupos reveló resultados prometedores y estadísticamente significativos para el aprendizaje de los alumnos de la clase experimental en relación con la clase de control. Además, un cuestionario contestado por ellos nos permitió comprobar que el uso de expresiones artísticas motivaba y despertaba interés, además de implicar y unir a todos los alumnos en torno a la producción.

Palabras clave: Enseñanza; Biología celular; Expresiones artísticas; Metodologías activas; Escuela secundaria.

\section{Introdução}

O conteúdo de Biologia é visto como desafiador por estudantes do Ensino Médio e, aparentemente, os principais motivos são os inúmeros nomes científicos, os complexos processos moleculares e os termos técnicos, fatores que dificultam a aprendizagem plena do conteúdo (Lima 2020; Queiroz et al., 2018). A Biologia Celular é a área da Biologia que estuda as Células, unidades microscópicas estruturais e funcionais dos seres vivos. Segundo Guimarães et al. (2016), o conteúdo nela estudado é alicerce para a compreensão da composição e de processos fisiológicos dos seres vivos. O autor ressalta, entretanto, que o ensino da disciplina demanda o uso de recursos didáticos diversos para que os alunos possam compreender a dinâmica celular, a morfologia das estruturas, bem como ter uma referência em relação às dimensões e funções das organelas.

Beaulieu e Petit-Turcotte (2018) apontam, inclusive, que a área é bastante fértil para aplicação de propostas lúdicas e interdisciplinares, uma vez que trabalha diretamente com estruturas microscópicas, com um vocabulário totalmente novo e abstrato para os estudantes. Vigario e Cicillini (2019) discutem que a natureza da disciplina apresenta uma forma de transcender a fragmentação curricular das áreas e dos conteúdos e adentrar a ciência do perceptível, bem como da construção de significados sobre a diversidade da vida. Elias e Gorla (2020) destacam de modo prático os resultados positivos na aprendizagem por meio de uma experiência interdisciplinar no ensino de Biologia Celular utilizando o desenho arquitetônico.

Assim, a aplicação da interdisciplinaridade no ensino do conteúdo relativo à célula parece ser uma proposta funcional na literatura. Entretanto, no ensino regular atual ainda persistem modelos fragmentadores. Enquanto as propostas interdisciplinares visam um ponto de cruzamento entre conteúdos com focos ou lógicas diferentes, a proposta educativa dominante mantém posições nitidamente delimitadas para os conteúdos, distanciando os estudantes da noção de que a construção do conhecimento na realidade é empírica, interpretativa e crítica, não sendo limitada e mecânica (Duarte et al., 2018; Pombo, 2008).

É fato que a partir da nova Lei de Diretrizes e Bases n 9.394/96 e dos Parâmetros Curriculares Nacionais (Brasil, 1998), iniciou-se um esforço no sentido de tornar o processo de ensino e aprendizagem sistêmico, diminuindo o viés estanque de conceitos e teorias em blocos. Em um novo esforço nesse sentido, a Base Nacional Comum Curricular também busca a quebra das barreiras disciplinares ao propor uma organização diferente das disciplinas na Educação Básica, a qual fortaleça as relações entre elas e a sua contextualização para apreensão e intervenção na realidade (Brasil, 2018). Ao propor a superação da fragmentação, o documento enfatiza que é preciso romper com a centralidade das disciplinas nos currículos e substituí-las por aspectos mais globalizadores, dando sentido ao que se ensina e abrangendo a complexidade das relações existentes entre os ramos da ciência no mundo real (Brasil, 2018).

Contudo, a tendência de muitos professores da Educação Básica ainda é de conduzir os conteúdos de sua disciplina dentro de seu próprio domínio, excluindo possíveis maneiras de integração com outros campos do conhecimento, o que reflete um pouco o modo cartesiano do ensino tradicional. Enxergando a necessidade de alterar esse cenário, pesquisadores têm sugerido o uso de metodologias ativas para a promoção da interdisciplinaridade, visto que estas promovem uma alternativa à organização 
escolar disciplinar e apresentam foco no aluno e em uma aprendizagem individual e autônoma (Berbel, 2011; Colorado, Mendoza e Valencia 2020; Santos et al. 2017; Sousa e Coelho 2020).

Dentre as metodologias ativas se destacam algumas com viés interdisciplinar, tais como: 1) os Estudos de Caso que analisam um fenômeno real levando em consideração o contexto em que está inserido e as variáveis que o influenciam e buscam, através do estudo de várias áreas, a solução para determinado problema (André, 2019); 2) a Aprendizagem Baseada em Projetos (ABP) que conduz um estudo, ou parte dele baseado em projetos envolvendo várias áreas do conhecimento para seu planejamento e execução (Santos et al., 2019); e 3) o Ensino Maker / hands on, no qual o aluno é instigado a construir suas próprias criações utilizando várias componentes curriculares (Lopes et al., 2019).

Além destas modalidades, pesquisas com projetos nas áreas do STEAM acrônimo do inglês para Science, Technology, Engineering, Arts e Mathematics, tem se tornado cada vez mais comuns e revelado uma íntima associação com propostas de metodologias ativas, visto que sugerem a aplicação da aprendizagem por meio de projetos integrando diversas áreas do conhecimento (Machado e Júnior, 2019). Logo, em essência a proposta envolve tanto a aplicação de metodologias ativas quanto da interdisciplinaridade.

Mas nem sempre a "Arte" esteve integrada no acrônimo, anteriormente conhecido apenas como STEM. Entre os primeiros proponentes da adição das Artes entre as ciências que compõem a educação STEM está o ex-presidente da Escola de Design de Rhode Island, John Maeda, o qual argumentou que a arte estimula a criatividade e a inovação, sendo coerente sua adição ao corpo de conhecimentos que tem esse fim como alvo (Maeda, 2013). Essa posição vem sendo corroborada por outros pesquisadores (Watson, 2015; Liao, 2016) os quais situam a educação em artes e o design como essenciais para o desenvolvimento de habilidades de pensamento e proposição de soluções alternativas.

Assim, além do aprofundamento da relação entre arte e ciência em projetos de pesquisa, a associação entre esses campos tem sido cada vez mais aplicada na educação, em contribuições de propostas interdisciplinares inovadoras e que envolvem metodologias ativas, visto que o campo da arte permite o desenvolvimento do pensamento criativo e disruptivo, além da prática da aprendizagem Maker / hands on (Cachapuz, 2014; Gomes, Sudério e Moura, 2020; Silveira, 2018). Além disso, como apontado pela literatura, as aulas nas quais o docente insere as expressões artísticas relacionadas ao conteúdo, com o intuito de auxiliar no processo de aprendizagem, proporcionam uma melhor compreensão do assunto abordado (Monteiro 2015). Isso porque, por definição, as expressões artísticas são métodos que auxiliam no processo de criatividade e estimulam o desenvolvimento social do indivíduo, ou seja, são maneiras de compreender as pessoas e o meio em que estão inseridas (Correia, 2009).

Trabalhos prévios revelaram o uso de expressões artísticas no ensino de biologia. O teatro, por exemplo, tem uma boa aceitação e conduz a uma participação ativa dos alunos. Para Silva e Gobara (2015), o teatro efetivamente contribui para provocar mudanças na forma de estudar e apreender os conteúdos a partir dos problemas de uma comunidade escolar. Já Menegazzo (2018) afirma que a experiência teatral no ensino de Biologia Celular foi útil, demonstrou resultados positivos relacionados à aprendizagem e à motivação dos estudantes.

Cavalcante (2011) destaca que o cinema e o trabalho pedagógico envolvendo filmes de longa e curta-metragem possibilitaram uma maior contextualização e autorreflexão por parte dos alunos e se mostrou uma metodologia atrativa capaz de atrair a atenção destes. No que diz respeito à música, outra expressão artística, Barros, Zanella e Jorge (2013) afirmam que, ao trabalhar com a música, os alunos demostram mais interesse na aula e, portanto, usá-la como instrumento facilitador do processo ensino-aprendizagem por professores de Ciências e Biologia é algo que deve ser incentivado.

Apesar de o potencial dessas ferramentas ter sido apontado na literatura, sua aplicação ainda é limitada, ou por desconhecimento de seu potencial e formas de aplicação, ou por falta de tempo para acessar pesquisas que apliquem propostas envolvendo expressões artísticas (Barros, Zanella e Jorge 2013; Silveira, 2018). 
Dado o exposto, a proposta dessa pesquisa levou em consideração o potencial do uso de expressões artísticas, a importância da aplicação da interdisciplinaridade e das metodologias ativas, para propor uma alternativa para o ensino de Biologia Celular no ensino médio. A investigação vem ao encontro das orientações presentes em documentos oficiais e traz subsídios para estudantes de licenciatura e professores atuantes que desejem aplicar propostas interdisciplinares em suas aulas. Toma-se com premissa que o uso das expressões artísticas para o Ensino de Biologia melhore o interesse e o rendimento dos alunos.

\section{Metodologia}

\subsection{Caracterização e delineamento da pesquisa}

Esta pesquisa se configura como descritiva-exploratória, de natureza aplicada, procedimento quase-experimental, com abordagem mista e design convergente (Prodanov e Freitas, 2013; Younas, Pedersen e Durante 2019). O design convergente envolve a coleta de dados qualitativos e quantitativos em paralelo - em nosso caso por meio de pré e pós-testes, do diário de campo e de um questionário final - com análise realizada separadamente, ocorrendo então uma integração para alcançar um entendimento mais profundo do fenômeno em análise (Younas, Pedersen e Durante 2019).

O delineamento da pesquisa para a aplicação da proposta envolveu as seguintes etapas: (i) planejamento das aulas de Biologia Celular no Ensino Médio junto à docente responsável pela disciplina; (ii) implementação de um teste piloto com uma turma controle e uma turma experimental; (iii) aplicação da avaliação diagnóstica e adaptação da sequência didática; (iv) aplicação da proposta com uma turma controle uma turma experimental; (v) aplicação do questionário em escala Likert; (vi) avaliação; (vii) análise de dados. A seguir, cada uma das etapas mencionadas será descrita, assim como o público-alvo da pesquisa.

\subsection{Público-alvo}

A aplicação da proposta ocorreu em uma escola pública de São Sebastião (DF) com turmas do $1^{\circ}$ ano do Ensino Médio. A escolha das turmas como experimental e controle foi feita por intermédio do diálogo com os professores de Biologia e de outras disciplinas das turmas de primeiros anos. Segundo os dados de avaliação dos docentes da turma que denominaremos " $1{ }^{\circ} \mathrm{F}$ " é a que possuía o melhor desempenho médio em várias componentes disciplinares. Segundo os mesmos professores, na turma aqui denominada " $1{ }^{\circ} \mathrm{H}$ " a maior parte dos alunos possuía desempenho abaixo da média. Por meio desse método, decidiuse que a turma $1^{\circ} \mathrm{F}$ fosse a turma controle, de modo a obter parâmetros para comparação com a turma experimental, que ficou sendo a turma $1^{\circ} \mathrm{H}$. As escolhas foram realizadas de modo a comparar a eficiência do método proposto em relação ao tradicional.

\subsection{Planejamento, aplicação e avaliação das aulas nas turmas experimental e controle}

Realizou-se inicialmente um teste piloto com uma turma controle e uma turma experimental, diferentes das que participariam da proposta, de modo a identificar possíveis problemas metodológicos no que diz respeito 1) ao tempo necessário para realização, 2) ao formato das aulas e 3) à elaboração dos instrumentos avaliativos. Após essa aplicação foi estruturada a sequência didática (tabela 1) à luz de Zabala (1998), a qual utilizou recursos comumente aplicados aos estudantes, de modo a não alterar o ritmo já seguido por esses alunos. 
Tabela 1. Síntese da Sequência Didática.

\begin{tabular}{|c|c|c|}
\hline \multicolumn{3}{|r|}{ SEQUÊNCIA DIDÁTICA } \\
\hline Aulas & Objetivos & $\begin{array}{l}\text { Atividades propostas } \\
\end{array}$ \\
\hline 2 & $\begin{array}{l}\text { Realizar um levantamento dos } \\
\text { conhecimentos prévios. } \\
\text { Apresentar a Biologia Celular e os } \\
\text { principais métodos de estudo das } \\
\text { células. }\end{array}$ & $\begin{array}{l}\text { Aplicação da avaliação diagnóstica. } \\
\text { Investigar as concepções prévias dos alunos sobre o assunto por meio de perguntas } \\
\text { introdutórias, tais como: Do que são formados os seres vivos? O que é uma célula? O } \\
\text { que é um microscópio e qual a sua importância? } \\
\text { Anotar pontos chave das respostas no quadro. } \\
\text { Explicação do conteúdo com auxílio de um projetor de slides. } \\
\text { Observação de lâminas de célula animal e vegetal com auxílio do microscópio. }\end{array}$ \\
\hline 1 & $\begin{array}{l}\text { Aprofundar a explanação do } \\
\text { conteúdo trabalhando conceitos } \\
\text { relacionados à composição da } \\
\text { Membrana Plasmática e suas } \\
\text { funções. }\end{array}$ & $\begin{array}{l}\text { Retomada do conteúdo apresentado na aula anterior. } \\
\text { Apresentação de um esquema da membrana e discussão dos elementos com os } \\
\text { estudantes. } \\
\text { Apresentação do conteúdo de forma investigativa, com auxílio do projetor de slides, } \\
\text { realizando perguntas e estimulando a participação. } \\
\text { Questionário para avaliar o conhecimento adquirido. }\end{array}$ \\
\hline 2 & $\begin{array}{l}\text { Aprofundar a explanação do } \\
\text { conteúdo trabalhando conceitos } \\
\text { relacionados à morfologia e } \\
\text { fisiologia das organelas. Comparar } \\
\text { célula animal e vegetal. }\end{array}$ & $\begin{array}{l}\text { Após a retomada de conteúdo, utilizar imagens modelo para que os estudantes } \\
\text { diferenciem célula procarionte da célula eucarionte, explicando as diferenças. Repetir o } \\
\text { processo para célula animal e vegetal. } \\
\text { Descrever as organelas (morfologia e fisiologia), estabelecendo comparação com os } \\
\text { órgãos do corpo. } \\
\text { Pedir que os estudantes desenhem os modelos legendando-os e destacando as principais } \\
\text { diferenças entre a célula animal e vegetal. }\end{array}$ \\
\hline 2 & $\begin{array}{l}\text { Síntese e finalização do conteúdo por } \\
\text { meio da apresentação do ciclo } \\
\text { celular e dos tipos de divisão celular. }\end{array}$ & $\begin{array}{l}\text { Retomada de conteúdo por meio de um jogo para que os estudantes rememorem todas } \\
\text { as aulas em ordem. } \\
\text { Apresentar o ciclo celular realizando um paralelo com o ciclo de nossas vidas. } \\
\text { Explicar os dois processos de divisão celular em etapas. } \\
\text { Pedir que os estudantes construam um resumo destacando as principais diferenças entre } \\
\text { mitose e meiose. }\end{array}$ \\
\hline 1 & Encerramento da proposta & Esclarecimento de dúvidas e Realização da prova. \\
\hline
\end{tabular}

Fonte: Autores (2021).

A partir da divisão das turmas acima descrita, todas responderam à avaliação diagnóstica (oral) antes do início das atividades de modo a identificar os conhecimentos prévios e verificar se seriam necessárias adaptações à sequência didática. Posteriormente, para a turma controle foi aplicada a sequência didática, enquanto para a turma experimental somente a primeira aula foi similar, as demais foram divididas entre momentos de apresentação do conteúdo, e momentos de aprendizado em grupo.

No que diz respeito à turma experimental, em detalhes, na primeira aula os estudantes foram divididos em grupos, em seguida, foi explicado a todos o que eram as expressões artísticas, sua importância no desenvolvimento de um pensamento criativo e no estímulo à inovação. Os estudantes foram convidados a participarem da discussão revelando quais expressões mais atraiam sua atenção ou mesmo aquelas que considerariam hábeis para desenvolver. Após esse momento, tendo feito o levantamento dos comentários dos estudantes, cada grupo escolheu trabalhar o conteúdo por meio de uma das seguintes expressões artísticas: música e artes visuais.

Após a divisão dos grupos, as atividades foram estabelecidas em conjunto com os alunos da seguinte forma: 1) no grupo da música, os estudantes deveriam trabalhar na composição de uma música autoral ou na criação de uma paródia; 2) nas artes visuais, um dos grupos trabalharia com uma maquete da célula ou de estruturas celulares em três dimensões, e 3) um segundo grupo atuaria com reprodução de desenhos que comporiam uma história em quadrinhos.

Todo o processo de criação dos trabalhos foi acompanhado pelo docente pesquisador, orientado por uma professora licenciada em Educação Artística e coorientado por uma professora doutora em Biologia Celular, de modo a auxiliar os alunos e assegurar que o conteúdo fosse abordado de forma correta, sem perder de vista conceitos relacionados a cada uma das expressões artísticas trabalhadas. Além disso, a docente responsável pela disciplina esteve sempre presente acompanhando a proposta. 
Nas aulas seguintes da turma experimental, as atividades foram divididas em dois momentos. Inicialmente o docente explicava o conteúdo de modo mais sintético e direto, focando nos conceitos essenciais. Em seguida, os estudantes dividiam-se em grupos, com um líder em cada grupo, de modo a direcionar as discussões e manter o foco no conteúdo apresentado, assim como na produção do produto que o grupo desenvolveria. Ressalta-se que o mesmo conteúdo textual (slides e textos) apresentados para a turma controle eram oferecidos aos grupos, de modo que pudessem estudar juntos.

Nesse momento o docente dividia o tempo restante de aula por cada um dos grupos, de modo que tivesse tempo disponível para todos. As perguntas que não eram respondidas naquele momento poderiam ser respondidas no horário de atendimento ao estudante pelo aplicativo WhatsApp. Esse horário era disponibilizado duas vezes por semana de modo que os grupos conseguissem obter retorno a respeito dos trabalhos e do conteúdo.

Após todas as aulas, uma data foi marcada para realização das apresentações na turma experimental. Ao final das apresentações, a turma experimental recebeu um questionário estruturado em Escala Likert (Quadro 1), com cinco níveis de concordância (Dalmoro e Vieira, 2013), de modo a quantificar aspectos qualitativos da proposta envolvendo metodologias ativas, interdisciplinaridade e expressões artísticas. Ressalta-se que itens similares foram adicionados às afirmações da escala, de modo a identificar estudantes que porventura estivessem apenas chutando aleatoriamente as respostas das questões. Caso as respostas de afirmações similares fossem contraditórias, os questionários poderiam ser eliminados da análise.

Quadro 1. Itens da escala do tipo Likert para avaliação de atitudes relacionadas à metodologia aplicada. A cada uma das afirmações, os estudantes deveriam responder marcando um dos seguintes itens: concordo totalmente, concordo, indiferente, discordo e discordo totalmente.

\begin{tabular}{|l|l|}
\hline & \multicolumn{1}{|c|}{ Afirmaç̃̃es da escala de avaliação de atitudes do tipo Likert } \\
\hline $\mathbf{1}$ & O trabalho com as expressões artísticas me ajudou a compreender melhor os assuntos relacionados à Biologia Celular. \\
\hline $\mathbf{2}$ & O trabalho com as expressões artísticas me ajudou a reter o conteúdo. \\
\hline $\mathbf{3}$ & Achei o trabalho com as expressões artísticas útil para o meu aprendizado. \\
\hline $\mathbf{4}$ & O trabalho com as expressões artísticas foi uma maneira divertida de aumentar a minha compreensão do tema. \\
\hline $\mathbf{5}$ & O trabalho com as expressões artísticas melhorou o meu conhecimento de Biologia Celular. \\
\hline $\mathbf{6}$ & O trabalho com as expressões artísticas ajudou a estimular minha criatividade. \\
\hline $\mathbf{7}$ & $\begin{array}{l}\text { O trabalho com as expressões artísticas deve continuar sendo usado como ferramenta para estudar morfologia e } \\
\text { função das organelas. }\end{array}$ \\
\hline $\mathbf{8}$ & O trabalho com as expressões artísticas me motivou a aprender Biologia Celular. \\
\hline $\mathbf{9}$ & O nível de satisfação foi maior que o de estresse na produção do trabalho. \\
\hline $\mathbf{1 0}$ & O trabalho com as expressões artísticas fez com que eu me sentisse mais preparado e confiante para provas. \\
\hline $\mathbf{1 1}$ & Prefiro aulas convencionais sem o uso dos trabalhos com as expressões artísticas. \\
\hline$*$ & Indique uma nota de 0 a 10 para a proposta de metodologia das aulas e dos trabalhos com as expressões artísticas. \\
\hline
\end{tabular}

Fonte: Autores (2021).

É válido pontuar que os produtos artísticos foram avaliados segundo uma rubrica de avaliação (tabela 2), sendo que os critérios para essa avaliação foram expostos para os estudantes no início da atividade e reforçados ao longo de todo o processo, de modo que estivessem claros os objetivos de aprendizagem da proposta e os estudantes pudessem ser direcionados a atender cada um dos itens expostos no momento do desenvolvimento do produto artístico.

Biagiotti (2004) aponta que as rubricas devem possuir algumas características de modo a tornarem-se ferramentas adequadas de avaliação. Dentre essas características, podemos citar: simplicidade e objetividade, granularidade apropriada (filtrar conceitos essenciais), gradação (níveis de análise) e herança, ou seja, a rubrica deve herdar as características da proposta escolhida, sendo assim, se a avaliação pretende avaliar a memorização, a rubrica deve permitir que esse aspecto seja avaliado. 
No caso da presente pesquisa, a rubrica e as correções foram validadas pelas docentes orientadoras da proposta e especialistas nas áreas de ensino de Artes e de Biologia Celular.

Tabela 2. Rubrica de avaliação.

\begin{tabular}{|c|c|c|c|c|c|}
\hline Critérios & & & Correção & & \\
\hline $\begin{array}{l}\text { 1. Quantidade de conceitos-chave do conteúdo de } \\
\text { Biologia Celular representados de forma correta } \\
\text { no produto artístico. }\end{array}$ & $\begin{array}{l}\text { Excelente } \\
(9,0-10)\end{array}$ & $\begin{array}{c}\text { Bom } \\
(8,9-7,0)\end{array}$ & $\begin{array}{l}\text { Regular } \\
(6,9-5,0)\end{array}$ & $\begin{array}{c}\text { Insatisfatório } \\
(4,9-3)\end{array}$ & $\begin{array}{l}\text { Refazer } \\
(2,9-0)\end{array}$ \\
\hline $\begin{array}{l}\text { 2. Aprofundamento no tema apresentado, os } \\
\text { produtos relevaram leitura e pesquisa sobre o } \\
\text { assunto. }\end{array}$ & $\begin{array}{l}\text { Excelente } \\
(9,0-10)\end{array}$ & $\begin{array}{c}\text { Bom } \\
(8,9-7,0)\end{array}$ & $\begin{array}{l}\text { Regular } \\
(6,9-5,0)\end{array}$ & $\begin{array}{l}\text { Insatisfatório } \\
\quad(4,9-3)\end{array}$ & $\begin{array}{l}\text { Refazer } \\
(2,9-0)\end{array}$ \\
\hline $\begin{array}{l}\text { 3. Coerência entre a descrição do produto artístico } \\
\text { e as técnicas escolhidas para sua produção e } \\
\text { apresentação. }\end{array}$ & $\begin{array}{l}\text { Excelente } \\
(9,0-10)\end{array}$ & $\begin{array}{c}\text { Bom } \\
(8,9-7,0)\end{array}$ & $\begin{array}{l}\text { Regular } \\
(6,9-5,0)\end{array}$ & $\begin{array}{c}\text { Insatisfatório } \\
\quad(4,9-3)\end{array}$ & $\begin{array}{l}\text { Refazer } \\
(2,9-0)\end{array}$ \\
\hline $\begin{array}{l}\text { 4. Criatividade na elaboração e apresentação do } \\
\text { produto artístico. }\end{array}$ & $\begin{array}{l}\text { Excelente } \\
(9,0-10)\end{array}$ & $\begin{array}{c}\text { Bom } \\
(8,9-7,0)\end{array}$ & $\begin{array}{c}\text { Regular } \\
(6,9-5,0)\end{array}$ & $\begin{array}{c}\text { Insatisfatório } \\
(4,9-3)\end{array}$ & $\begin{array}{l}\text { Refazer } \\
(2,9-0)\end{array}$ \\
\hline $\begin{array}{l}\text { 5. Participação de todos os estudantes ao longo do } \\
\text { processo em cada uma das aulas. }\end{array}$ & $\begin{array}{l}\text { Excelente } \\
(9,0-10)\end{array}$ & $\begin{array}{c}\text { Bom } \\
(8,9-7,0)\end{array}$ & $\begin{array}{l}\text { Regular } \\
(6,9-5,0)\end{array}$ & $\begin{array}{c}\text { Insatisfatório } \\
(4,9-3)\end{array}$ & $\begin{array}{l}\text { Refazer } \\
(2,9-0)\end{array}$ \\
\hline
\end{tabular}

Fonte: Autores (2021).

Por fim, tanto a turma experimental quanto a turma controle realizaram a prova da disciplina. A prova foi composta por 10 questões, conforme descrito no quadro abaixo. Essa avaliação foi estruturada por meio da Taxonomia de Bloom (Krathwohl, 2002), que utiliza a organização hierárquica para classificar questões de acordo com as habilidades por elas requeridas. O intuito era justamente verificar se determinadas questões foram melhor desenvolvidas na turma experimental com relação à turma controle, além de comparar o rendimento geral entre ambos.

Quadro 2. Questões do teste avaliativo aplicado nas turmas controle e experimentais.

\begin{tabular}{|c|c|c|c|}
\hline Tipo da Questão & Enunciado & Nível & $\begin{array}{c}\text { Habilidades (Taxonomia de } \\
\text { Bloom) }\end{array}$ \\
\hline Correspondência & $\begin{array}{l}\text { Identifique e aponte na coluna da direita } \\
\text { organela correspondente de acordo com a sua } \\
\text { função. }\end{array}$ & $\begin{array}{l}\text { Básico. } \\
\text { Conhecimento e } \\
\text { compreensão }\end{array}$ & $\begin{array}{l}\text { Observação, recordação e } \\
\text { entendimento de informações; } \\
\text { Domínio da matéria }\end{array}$ \\
\hline Múltipla Escolha & $\begin{array}{l}\text { De acordo com a Teoria Celular podemos } \\
\text { afirmar. }\end{array}$ & $\begin{array}{l}\text { Básico. } \\
\text { Conhecimento. }\end{array}$ & $\begin{array}{l}\text { Observação de recordação de } \\
\text { informações }\end{array}$ \\
\hline $\begin{array}{l}\text { Múltipla Escolha e Resposta } \\
\text { Curta }\end{array}$ & $\begin{array}{l}\text { Analise as imagens abaixo (figura A e figura } \\
\text { B), obtidas a partir da microscopia óptica e } \\
\text { responda: Qual imagem corresponde à célula } \\
\text { vegetal e qual corresponde à célula animal. } \\
\text { Justifique. }\end{array}$ & $\begin{array}{l}\text { Intermediário. } \\
\text { Análise e } \\
\text { Aplicação. }\end{array}$ & $\begin{array}{l}\text { Uso de informação e } \\
\text { identificação de componentes }\end{array}$ \\
\hline Verdadeiro/Falso & $\begin{array}{l}\text { Sobre Mitose e Meiose identifique a(s) } \\
\text { alternativa(s) } \underline{\operatorname{VERDADEIRA}(S)} \text {. }\end{array}$ & $\begin{array}{l}\text { Básico. } \\
\text { Conhecimento e } \\
\text { compreensão }\end{array}$ & $\begin{array}{l}\text { Apreensão de significado, } \\
\text { conhecimento das ideias } \\
\text { principais, domínio da matéria } \\
\text { e comparação }\end{array}$ \\
\hline $\begin{array}{l}\text { Verdadeiro/Falso e } \\
\text { Resposta Curta }\end{array}$ & $\begin{array}{l}\text { Leia atentamente as afirmativas abaixo e julgue } \\
\text { (V) para VERDADEIRO e (F) para FALSO. } \\
\text { Justifique as afirmativas marcadas como } \\
\text { FALSO. }\end{array}$ & Global. Avaliação & Julgamento do valor de teorias \\
\hline Múltipla Escolha & Marque a alternativa correta. & $\begin{array}{l}\text { Básico. } \\
\text { Conhecimento. }\end{array}$ & $\begin{array}{l}\text { Recordação das informações e } \\
\text { domínio da matéria }\end{array}$ \\
\hline Correspondência & $\begin{array}{l}\text { Utilize as palavras abaixo para preencher } \\
\text { corretamente as lacunas do texto }\end{array}$ & $\begin{array}{l}\text { Intermediário. } \\
\text { Aplicação }\end{array}$ & Uso de informação \\
\hline
\end{tabular}




\begin{tabular}{|l|lll|} 
Resposta Curta & $\begin{array}{l}\text { Observe atentamente a imagem abaixo, } \\
\text { identifique e escreva o nome das organelas } \\
\text { indicadas. }\end{array}$ & $\begin{array}{l}\text { Intermediário. } \\
\text { Análise }\end{array}$ & $\begin{array}{l}\text { Identificação de componentes e } \\
\text { organização em partes }\end{array}$ \\
Múltipla Escolha & $\begin{array}{l}\text { Analise o texto a seguir e assine a alternativa } \\
\text { que preencha corretamente as lacunas abaixo. }\end{array}$ & $\begin{array}{l}\text { Intermediário. } \\
\text { Aplicação }\end{array}$ & Uso de informação \\
Múltipla Escolha & $\begin{array}{l}\text { A respeito da microscopia assinale a alternativa } \\
\text { CORRETA. }\end{array}$ & $\begin{array}{l}\text { Básico. } \\
\text { Conhecimento. }\end{array}$ & $\begin{array}{l}\text { Observação e recordação de } \\
\text { informação }\end{array}$ \\
\hline
\end{tabular}

Fonte: Autores (2021).

A comparação entre as provas da turma controle e da turma experimental foi feita tendo em vista a média das turmas, e uma análise por questão, de modo a verificar se houve diferença estatisticamente significativa em algumas questões em relação a outras. As comparações foram feitas por meio do teste estatístico $t$ Student com nível de significância de 0,05 (95\%).

Ressalta-se que todas as etapas do processo foram registradas em diário de campo de modo a relatar aspectos que não poderiam ser levantados por meio do questionário ou da prova, tais como gestos, expressões de ânimo ou desânimo e o comportamento geral dos estudantes durante a realização das atividades nas duas turmas (Demo, 2012; Araújo et al., 2013).

Para análise do conteúdo do diário de campo seguiu-se a abordagem de Freitas e Pereira (2018), em seu trabalho intitulado "O diário de campo e suas possibilidades". Na proposta dos autores, a análise foi combinada à estruturação de três núcleos de significação. Em concordância com o exposto, os pesquisadores definiram dois núcleos similares: 1) impressões e sentimentos dos estudantes sobre a experiência nos momentos de execução; e 2) reflexões do docente sobre a ação. Após a classificação dos trechos, estes foram combinados e descritos, nos resultados em associação com a descrição de cada um dos momentos de aplicação da atividade.

Dessa forma, os principais instrumentos utilizados para o levantamento de dados foram o diário de campo, o questionário em escala Likert, a rubrica de avaliação dos produtos e a prova.

\section{Resultados e Discussão}

\subsection{Aplicação da proposta na turma controle e na turma experimental: dados obtidos por meio do diário de campo}

Após a aplicação da avaliação diagnóstica, foi registrado em diário de campo o comportamento de resposta dos estudantes. Poucos alunos manifestaram-se para responder as questões relacionadas às células. As perguntas tinham em vista o conteúdo já apresentado aos estudantes no ensino fundamental, segundo preconizado em documentos oficiais, como os estabelecidos pelos PCN (Brasil, 1998). Entretanto, poucos estudantes manifestaram comentários mais profundos sobre seus conhecimentos relacionados às células, o que se demonstrou um estímulo importante para abordar o conteúdo de maneira marcante e significativa. Isso porque a temática é alicerce para compreensão de outros conteúdos relacionados à morfologia e fisiologia dos seres vivos.

A avaliação diagnóstica permitiu a finalização da sequência didática (Quadro 1) e sua aplicação na turma controle. Sobre as reações da turma controle durante as aulas, foi registrado em diário de campo:

"Na maior parte do tempo a turma estava dispersa. Era possível perceber que nos primeiros 10/15 minutos os alunos estavam atentos, mas depois disso alguns deles já estavam bocejando, dormindo ou conversando." (Diário de campo, 2019).

Ressalta-se que os únicos momentos em que a turma participou mais ativamente foram na realização do jogo de revisão e quando insistentemente questionados pelo docente se tinham dúvidas e se estavam compreendendo a matéria. Assim, a maior parte do tempo durante todas as aulas os estudantes manifestaram pouco ou nenhum protagonismo na discussão do conteúdo e na construção do próprio aprendizado. 
O protagonismo e a autonomia do estudante precisam ser estimulados, as situações de aprendizagem precisam ser criadas pelo docente, de modo que os alunos assumam essa posição de maneira ativa e participativa (Volkweiss et al., 2019). Como afirmado por Volkweiss e colaboradores (2019) ser protagonista da sua aprendizagem não é algo trivial para os alunos, convém um olhar atento por parte do docente, é preciso exercer o papel de mediador e motivador, de modo a estimular os estudantes a assumirem esse importante papel formativo.

Tal comportamento foi visualizado na turma experimental de maneira mais frequente, com dúvidas sendo expostas e interesse por parte dos alunos de participar da construção da aula e da explicação do conteúdo. O diário de campo revela a presença de alguns estudantes que mantiveram uma postura tímida e uma participação mais esporádica, mas em grupos menores, com colegas mais próximos, mesmo esse comportamento foi bem menos frequente.

Além da aproximação da arte com a biologia, fato que gerou interesse por parte dos estudantes, o qual tem sido preconizado na literatura (Silva e Fraga, 2017), a realização da atividade tendo em vista um projeto realizado por um grupo de estudantes, também foi responsável por alguns comentários positivos dos estudantes da turma experimental quando abordados pelo docente. Isso porque pesquisadores apontam que aprender, tendo como foco o desenvolvimento de um projeto em comum, proporciona motivação, engajamento e, em muitos casos, contribuições à comunidade na qual os alunos estão inseridos (Bender, 2014). A troca de saberes permitida pela ABP, torna mais atrativo e acessível o aprendizado de disciplinas científicas consideradas complexas por parte dos estudantes da educação básica (Pasqualetto, Veit e Araujo, 2017).

Tais referências corroboram o exposto no diário de campo com relação ao comportamento da turma experimental, tal como exposto no trecho abaixo:

"Durante os atendimentos aos grupos foi possível perceber um maior envolvimento e interesse dos alunos com o conteúdo e como eles poderiam abordar os assuntos na modalidade artística escolhida por eles. Os estudantes aprofundavam os temas por conta própria. Um grupo que ficou com maquete sobre célula procarionte me chamou para perguntar se as bactérias apresentam sempre cílios e flagelos ao mesmo tempo, pois no livro os desenhos ilustravam que sim, mas na internet dizia que a bactéria poderia apresentar ou cílios ou flagelos, mas nunca os dois ao mesmo tempo" (Diário de campo, 2019).

Com relação aos desafios pontuados no diário de campo, além da apatia da turma controle, foi possível identificar que os grupos da turma experimental algumas vezes desfocavam do objetivo da aula, sendo necessário que o docente fizesse chamadas frequentes para o retorno ao objetivo preconizado. Também foi ressaltado nas anotações e reflexões que a presença de um líder nos grupos era essencial, de modo que o docente pudesse cobrar apenas dele um comportamento adequado por parte do grupo. O estudante designado agia como um colaborador voltando a atenção dos estudantes para o alvo.

Entretanto, apesar da energia demandada para a organização e manutenção da atenção dos grupos, uma das anotações presentes no diário de campo permitiu identificar que, a energia gasta para ministrar uma aula de modo predominantemente expositivo é alta e poucos estudantes envolvem-se ou adquirem habilidades de fato nesses momentos. Isso porque a capacidade de seleção e tratamento de informações, debates e transposição de conhecimentos, colaboração e a capacidade de trabalhar de forma cooperativa são habilidades que podem ser mais bem trabalhadas quando atividades coletivas são estimuladas (Pasqualetto; Veit e Araujo, 2017).

Quando analisados o comportamento dos estudantes da turma controle, registrados no diário de campo durante e após a aplicação das aulas, estes revelam que as atividades não fugiram do convencional, que não se sentiram motivados a participar ou mesmo envolvidos na construção do próprio conhecimento. A exemplo dessas observações, podemos citar:

"Durante a produção dos seminários das turmas controle não houve nenhuma procura por atendimento e, nas aulas, grande parte dos grupos anotavam e davam atenção apenas ao tema destinado a eles ignorando os demais conteúdos. Durante as apresentações dos trabalhos não foi diferente, enquanto um grupo apresentava os outros estavam estudando o que iriam falar, e alguns componentes dos grupos que já tinham apresentado começavam a conversar, foi necessário 
chamar a atenção da turma para que respeitassem o trabalho dos colegas, inclusive, a professora regente informou que iria diminuir a nota dos alunos que atrapalhassem as apresentações dos demais grupos. ” (Diário de campo, 2019).

Com relação aos comentários tecidos pelos estudantes da turma experimental, foi possível identificar dois tipos de posicionamento:

\begin{abstract}
"No início da aplicação da proposta um aluno me questionou se não haveria aula (referindo-se ao modelo tradicional) ou revisão para a prova, então foi necessário ter uma conversa com a turma para explicar que eles teriam que confiar nos colegas para aprender com eles através do método que estava sendo aplicado, acrescentei ainda que eles não precisavam se preocupar, pois os conteúdos seriam abordados de forma correta, visto que eu mesmo estava orientando os grupos para garantir que o conteúdo seria abordado corretamente, por outro lado, alguns alunos alegaram e demostraram estar curiosos para ver o trabalho dos outros grupos, uma aluna chegou a falar que estava curiosa pois "tudo era feito em segredo". Ao 'andar da carruagem' foi perceptível o envolvimento e comprometimento dos alunos, alguns levavam violão para ensaiar a paródia em sala de aula durante o intervalo. Durante a apresentação dos trabalhos foi notável o respeito dos colegas com os trabalhos desenvolvidos pelos grupos, houve momento de descontração, alguns grupos se mostravam mais tranquilos e confiantes, outros se mostraram mais nervosos (principalmente os grupos de teatro e música/paródia). De modo geral, acredito que os estudantes entenderam que cada grupo se empenhou na sua área artística de afinidade elou domínio, cada trabalho teve o seu valor." (Diário de campo, 2019).
\end{abstract}

No geral, os registros no diário de campo permitiram identificar um elevado nível de interesse e empolgação por parte dos alunos da turma experimental, oposto ao comportamento identificado na turma controle. Os dados concordam com o exposto por Adkins, Rock e Morris (2018, p. 4), os quais afirmam que "a arte tem a capacidade de enriquecer o ensino de Ciências de várias maneiras, aumentando a atenção para os detalhes, melhorando o senso de propriedade dos alunos sobre seu trabalho por meio da personalização das obras criadas por eles”.

\title{
3.2 Descrição e avaliação dos produtos artísticos desenvolvidos pelos estudantes da turma experimental
}

A seguir descreveremos cada um dos produtos desenvolvidos pelos grupos durante as aulas, bem como o resultado da avaliação da proposta por meio do questionário em escala Likert.

O primeiro grupo desenvolveu modelos didáticos tridimensionais de células procarióticas e eucarióticas, utilizando materiais recicláveis, de baixo custo e fácil obtenção, a justificativa do grupo para o desenvolvimento da proposta e a explicação dos produtos revela associação com o exposto na literatura, visto que os estudantes apontam para a melhor compreensão das estruturas que compõem as células e suas dimensões em escala (Silva, Silva e Silva, 2018). Os estudantes também reforçaram o aprendizado de habilidades artísticas na execução da proposta, visto que ao buscar instruções a respeito do material, foram orientados sobre técnicas mais apropriadas para a construção de modelos estáveis e duráveis. Esse é um dos motivos apresentados por Silva e Fraga (2017) sobre a importância em aproximar as duas áreas do conhecimento: a Biologia e a Arte.

Na confecção dos modelos, foi notável que os alunos empregaram seus hobbies ou experiencias obtidas anteriormente na confecção das peças, isso ficou claro quando, por exemplo, um dos alunos optou por fazer estruturas em argila enquanto os outros grupos estavam trabalhando com massinha de modelar. Tal aluno alegou ter mais afinidade com o material, pois já havia trabalhado com esta técnica antes.

Um segundo grupo optou por produzir paródias sobre a membrana plasmática. Túrmina e Rodrigues (2016) encontraram resultado positivo em sua pesquisa com aplicação de paródias, tendo em vista a interação e comprometimento dos alunos envolvidos na proposta. O mesmo comprometimento foi observado nos estudantes que desenvolviam as letras das músicas tomando como base melodias conhecidas por eles, fato que gerou maior disposição para a construção das letras. Além das possibilidades de desenvolvimento de rimas, os estudantes foram apresentados aos conceitos de paródia e à importância do direito à autoria nas produções musicais. 
O grupo envolvido na proposta ressaltou sua utilidade para a memorização de conceitos, fato que foi corroborado pela turma ao assistir à apresentação. O uso de paródias no ensino não é novo, e é largamente utilizado por professores em cursos preparatórios para vestibulares e para o Enem, justamente pelo potencial para possibilitar a memorização de conceitos (Cabral, 2009). Essa habilidade também é importante no aprendizado e deve ser estimulada junto ao pensamento crítico e analítico.

A utilização da música, mais especificamente da paródia, como recurso para o ensino de Biologia Celular se mostrou eficiente para a assimilação, compreensão e memorização do conteúdo trabalhado, além de motivar o aluno a aprender constantemente. No Quadro 3 é demonstrado um exemplo de paródia elaboradas pelos alunos sobre a membrana plasmática.

Quadro 3 - Exemplo de uma das paródias elaboradas pelos alunos.

\section{Paródia 03 - Membrana Plasmática \\ (PARÓDIA DA MÚSICA “AI, QUE SAUDADE D'OCÊ” - ZECA BALEIRO)}

Não se admire se um dia eu falar que aprendi / a matéria de biologia com essa música aqui / A membrana plasmática ou plasmalema / É um envoltório fino que reveste as células / Tem as funções que 'é' fácil de aprende / Proteção, seleção e revestimento para fazer / Tudo que entra e sai é controlado direitinho / Por essas funções que fazem tudo certinho / A estrutura da membrana é proteínas e lipídios / Aí a gente se ferra, porque fica tudo difícil / Mas calma, não precisa se apavorar / A professora 'malvadeza' não vai nos reprovar / Lipídios são compostos químicos orgânicos que ocorre nos seres vivos / Mas calma, não fique aflito, pois a proteína é a mais importante das Macromoléculas tendo mais da metade do peso de uma célula / E pra terminar eu quero agradecer / Os professores que ajudaram a gente a aprender / Então segura essa turma que é o $1^{\circ} \mathrm{G} /$ 'Chicão' que se prepare, pois hoje é dia de maldade.

Fonte: Autores (2021).

Analisando as letras das paródias foi possível identificar traços das músicas originais e algumas adaptações de letra que configuram humor, em alguns momentos o grupo manteve o início e final de alguns versos das músicas originais e trocaram algumas palavras por termos intrínsecos da Biologia Celular. O uso de pedaços originais das músicas ajuda a manter a métrica ${ }^{1}$ musical, conceito explicado para os estudantes durante as orientações. Além disso, tais trechos são importantes pois se tornam pontos de memorização. Quanto ao conteúdo foi possível inferir que os grupos exploraram e compreenderam as principais moléculas que compõem a membrana e suas funções, em especial os tipos de transporte realizados na membrana.

Vale ressaltar que, em registro no diário de campo, o docente destaca que as turmas se divertiram bastante durante a apresentação das paródias, a letra foi projetada e as músicas foram apresentadas ao vivo e mais de uma vez, de modo que na segunda repetição, os alunos pudessem acompanhar os grupos cantando juntamente com eles.

Outro grupo optou por elaborar uma História em Quadrinhos (HQ), essa linha de expressão artística demanda que o artista repita várias vezes o mesmo desenho com o personagem/objeto em posições diferentes e, antes mesmo de inserir o texto, as imagens já devem seguir uma ordem lógica da história para que o observador consiga entender os elementos da história e do que ela trata (Marafigo, 2019). Os estudantes não só atenderam a proposta como desenharam várias páginas em sequência de um material que foi distribuído para que a turma pudesse ter acesso e acompanhar a história e os conceitos ali descritos.

Pela leitura e avaliação dos conceitos presentes nos recursos foi possível identificar que o grupo responsável pela confecção da HQ demostrou compreender a importância dos microscópios para o estudo das células e os principais cientistas

\footnotetext{
${ }^{1}$ Métrica, em música, é a divisão de uma sequência melódica com ou sem texto em tempos fortes e fracos. Nas canções, a divisão tende a coincidir com a acentuação das palavras, ou seja, com o posicionamento da sílaba tônica.
} 
envolvidos na criação da teoria celular e como ela foi constituída, ficou claro que o processo foi demorado e que as descobertas ao logo do tempo foram fundamentais para o desenvolvimento da Biologia Celular como a conhecemos hoje.

Com relação à avaliação, é possível perceber que as notas referentes a cada um dos critérios da rubrica (tabela 3) indicam que os estudantes atenderam o esperado. De modo geral, todos os grupos apresentaram domínio do conteúdo referente ao tema dos trabalhos destinados a eles. Para confeccionar as peças foram necessárias pesquisas as quais se estenderam para além dos livros didáticos e durante os atendimentos foi possível sanar dúvidas que não seriam levantadas em uma aula com o método tradicional de ensino. Para confeccionar as peças ou elaborar as paródias e HQs, os estudantes precisaram entender mais profundamente o conteúdo, o senso de responsabilidade e o acompanhamento foram fatores relevantes para o preparo e a forma de apresentação para os colegas.

Tabela 3. Notas de cada um dos grupos nos critérios da rubrica de avaliação.

\begin{tabular}{|c|c|c|c|c|c|}
\hline \multirow[t]{2}{*}{ Grupos } & \multicolumn{5}{|c|}{ Critérios / Conceito / Nota } \\
\hline & 1 & 2 & 3 & 4 & 5 \\
\hline \multirow[t]{2}{*}{ Modelo Tridimensional } & Excelente & Bom & Bom & Excelente & Excelente \\
\hline & $(9,1)$ & $(8,2)$ & $(7,1)$ & $(9,1)$ & $(9,5)$ \\
\hline \multirow{2}{*}{ Paródia } & Excelente & Excelente & Bom & Bom & Bom \\
\hline & $(9,3)$ & $(9,0)$ & (7) & (8) & $(8,6)$ \\
\hline \multirow{2}{*}{ História em Quadrinhos } & Bom & Excelente & Insatisfatório & Bom & Bom \\
\hline & $(7,4)$ & (9) & $(4,7)$ & & $(7,1)$ \\
\hline
\end{tabular}

Fonte: Autores (2021).

Todo o processo foi uma troca de experiências e técnicas que respingaram em diversas áreas do cotidiano dos alunos, ultrapassando os limites da disciplina de biologia. Houve muita interação entre os alunos, participação no momento das apresentações, e respeito com o trabalho dos colegas, o que proporcionou momentos de diversão e aprendizagem para a turma experimental.

O envolvimento e a opinião dos estudantes sobre a proposta podem ser identificados também por meio da avaliação em escala Likert. Os resultados indicados na Figura 1 revelam que a maior parte dos alunos consideram que compreenderam melhor os assuntos e retiveram os conteúdos relacionados à Biologia Celular por meio do uso das expressões artísticas (91,43\% e 77,14\%, respectivamente). Os resultados obtidos nesta pesquisa corroboram com aqueles encontrados por Adkins, Rock e Morris $(2018$, p. 6) que concluem que a inclusão de artes com o ensino de Ciências "pode ser uma estratégia eficaz para melhorar o domínio dos conteúdos de ciência, bem como aumentar a diversão e envolvimento dos alunos".

Para $91 \%$ dos estudantes o método que utiliza as expressões artísticas e as metodologias ativas deve continuar sendo utilizado como ferramenta de estudo para a Biologia Celular. Além disso, $60 \%$ dos alunos afirmaram também que o nível de satisfação foi maior do que o de estresse na produção dos trabalhos. Segundo Colorado, Mendoza e Valencia (2020, p. 2), um dos principais fatores que aumenta o prazer na produção dos trabalhos é o fato de que "os alunos podem cooperar ativamente uns com os outros, maximizando assim a aprendizagem".

Além disso, $91 \%$ dos alunos afirmam que o trabalho foi útil para o aprendizado, e que $80 \%$ acharam que o trabalho foi uma maneira divertida de aprender. Tais resultados corroboram com os resultados de Santos, Gadelha e Bandeira (2019, p.05), os quais afirmam que "foi possível perceber que as metodologias inovadoras fazem uma grande diferença em sala de aula, 
além de trazer uma dinamicidade e um conteúdo de forma lúdica e divertida, fazendo com que o acadêmico seja o foco e ganhe autonomia e experiência".

Figura 1. Análise das respostas à escala Likert. Na coluna à esquerda é possível observar a lista de itens que as participantes julgaram. Na coluna à direita os níveis de concordância por cores: Azul (Concordo Totalmente ou Concordo), Vermelho (Indiferente), Verde (Discordo Totalmente ou Discordo) e Roxo (Em Branco).

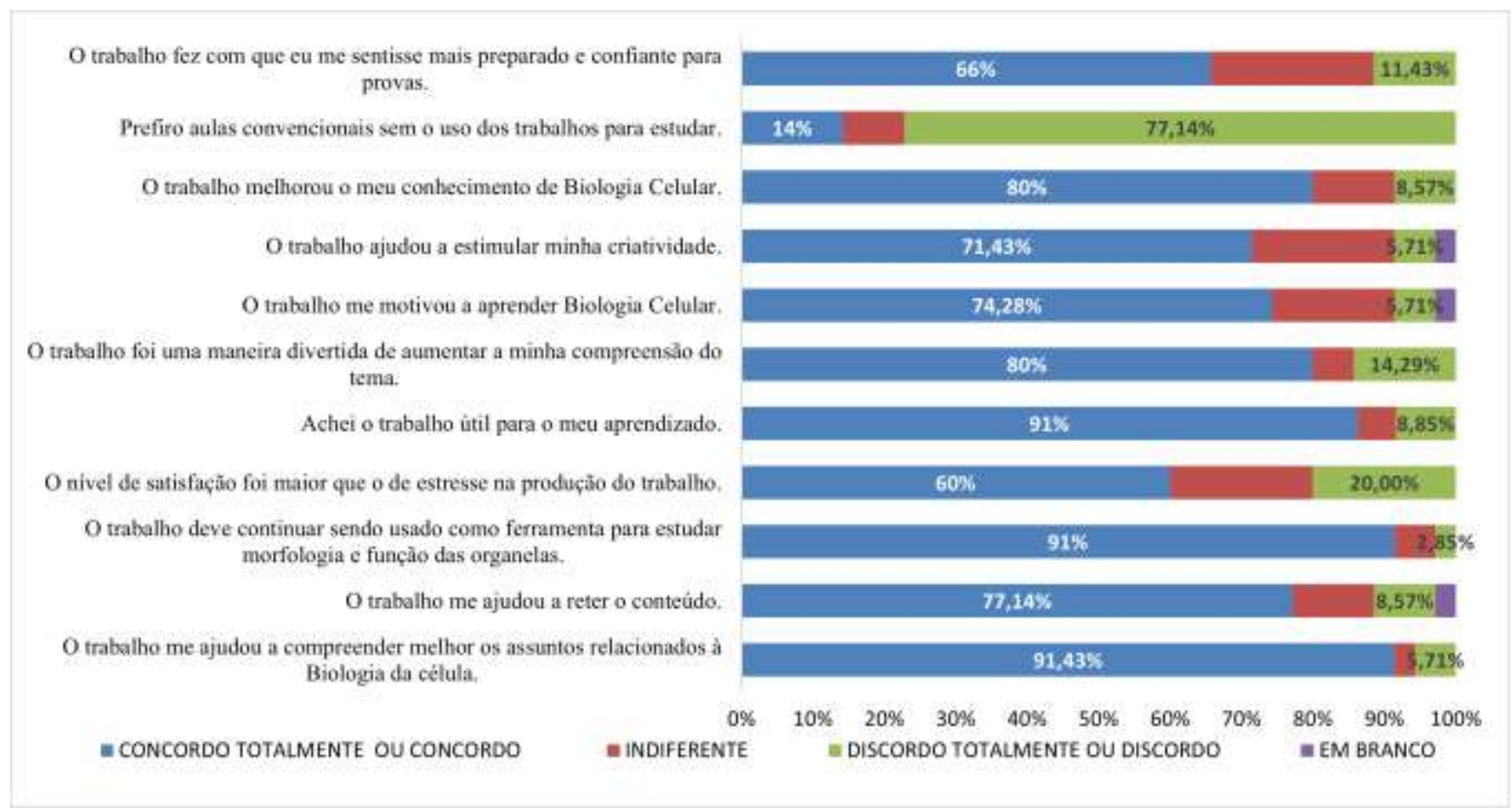

Fonte: Autores (2021).

Mais de 74\% dos alunos afirmaram que se sentiram motivados a aprender Biologia Celular devido a aplicação do método das expressões artísticas e mais de $71 \%$ afirmaram que o trabalho ajudou a estimular a criatividade. Sendo assim, os resultados encontrados nesta pesquisa confirmam o que Morin e Lüdke (2020, p.18) afirmam sobre o ensino de Ciência "se tornar mais atraente com o uso de aulas diferenciadas, bem planejadas e que fogem do contexto tradicional expositivo".

Os alunos também afirmaram obter uma melhor aprendizagem com o trabalho e que assim se sentem mais confiantes e preparados para a prova e concordam que preferem aulas com as metodologias ativas que envolvem as expressões artísticas do que com os métodos convencionais (77\%).

Uma última pergunta foi adicionada ao questionário de opinião em escala Likert, nela, os alunos foram convidados a avaliar, de 0 a 10, qual seria o nível de satisfação ao realizar o trabalho proposto. À essa pergunta, cerca de $80 \%$ afirmaram que a nota seria 10, ou seja, apontaram satisfação total em relação ao uso das expressões artísticas no ensino de Biologia Celular. Segundo Morin e Lüdke (2020, p.18), "no ensino de Biologia, as aulas expositivas comumente têm sido a única metodologia utilizada nas salas de aulas, cultivando a ideia de que o trabalho com a disciplina é sempre cansativo e desinteressante”. Sendo assim, os resultados dessa pesquisa demonstram que, quando a metodologia é modificada, bem planejada, de acordo com os princípios expostos em documentos oficiais e na literatura, o processo de aprendizagem se torna mais satisfatório. Conforme menciona Sumida e Jefcoat (2018, p.1277), "a ciência e arte juntas podem ser muito maiores do que a soma das partes em separado". 


\subsection{Resultados da análise estatística tendo como base os dados da prova}

Após as aulas e apresentações, os estudantes fizeram a prova da disciplina. A prova foi composta por questões abertas e fechadas, com variações no nível de dificuldade, conforme a taxonomia de Bloom.

Tabela 4. Média final e média das notas por questão da Turma Controle (T.C.) e da Turma Experimental (T.E.).

\begin{tabular}{c|c|c|c|c|c|c|c|c|c|c|c}
\hline Questões & $\mathbf{Q 1}(\overline{\mathbf{x}})$ & $\mathbf{Q 2}(\overline{\mathbf{x}})$ & $\mathbf{Q 3}(\overline{\mathbf{x}})$ & $\mathbf{Q 4}(\overline{\mathbf{x}})$ & $\mathbf{Q 5}(\overline{\mathbf{x}})$ & $\mathbf{Q 6}(\overline{\mathbf{x}})$ & $\mathbf{Q 7}(\overline{\mathbf{x}})$ & $\mathbf{Q 8}(\overline{\mathbf{x}})$ & Q9 $(\overline{\mathbf{x}})$ & Q10 $(\overline{\mathbf{x}})$ & Média Prova \\
\hline T.C. & 0.13 & 0.09 & 0.09 & 0.05 & 0.08 & 0.05 & 0.18 & 0.06 & 0.08 & 0.03 & $\mathbf{0 . 8 2}$ \\
\hline T.E. & 0.14 & 0.08 & 0.10 & 0.11 & 0.06 & 0.07 & 0.18 & 0.13 & 0.14 & 0.03 & $\mathbf{1 . 0 1}$ \\
\hline $\begin{array}{c}\text { Teste } \boldsymbol{t} \\
\text { (p valor) }\end{array}$ & $\mathbf{0 . 3 4 9}$ & $\mathbf{0 . 1 1 2}$ & $\mathbf{0 . 3 4 4}$ & $\mathbf{0 . 0 0 3}$ & $\mathbf{0 . 2 3 9}$ & $\mathbf{0 . 0 3 8}$ & $\mathbf{0 . 2 8 8}$ & $\mathbf{0 . 0 0 3}$ & $\mathbf{0 . 0 1 9}$ & $\mathbf{0 . 2 8 3}$ & $\mathbf{0 . 0 1 6}$ \\
\hline
\end{tabular}

Fonte: Autores (2021).

Pelos valores indicados na tabela 4 é possível identificar que houve diferença estatisticamente significativa entre as médias das provas das turmas controle e experimental, sendo que esta apresenta uma média maior. Esse rendimento pode ser um indicativo de um aprendizado maior do conteúdo em relação à turma controle, corroborando as opiniões dos estudantes expressas no questionário de opinião, assim como as reações reveladas pelas descrições no diário de campo e na literatura atual (Barros, Zanella e Jorge 2013; Menegazzo, 2018; Silva e Fraga 2017; Silva, Silva e Silva, 2018; Silva e Gobara, 2015; Túrmina e Rodrigues, 2016)

Um olhar mais detalhado sobre o resultado das provas, revela que apenas nas questões 2 e 5 a turma controle obteve nota ligeiramente maior que a turma experimental, nas demais questões, apesar de não haver diferença estatisticamente significativa ( $\mathrm{p}<0,05$ ), a turma experimental teve rendimento maior (questões 1, 3, 4, 6, 8 e 9) ou igual (questões 7 e 10) em $80 \%$ das questões.

Dentre as questões que a turma experimental apresentou melhor rendimento, destacam-se 4,8 e 9 , as quais revelam diferença estatisticamente significativa com relação à turma controle. Na questão 4 os estudantes deveriam identificar itens verdadeiros relacionados à divisão celular (mitose e meiose) e, em seguida, assinalar a alternativa correta. Na questão 8 os estudantes deveriam identificar as organelas apontadas na imagem e nomeá-las. Ou seja, ambas estão relacionadas a habilidades de memorização e compreensão (lembrar e compreender) as quais podem ter sido melhor assimiladas justamente pelo desenvolvimento das expressões artísticas (Bastos e Faria, 2011; Menegazzo, 2018; Barros, Zanella e Jorge 2013; Silveira, 2018).

Já na questão 9 os estudantes deveriam analisar um trecho de um texto sobre o transporte na membrana, relacionando os conceitos nele apresentados para completar as informações faltantes com as alternativas disponíveis. Esse item está relacionado a habilidades de análise e compreensão, corroborando com os resultados obtidos nas pesquisas de Costa e Vieira (2018); Heinz, Quintana e Cruz (2019); Santos e Amorim (2020), os quais afirmam que a aplicação de metodologias ativas no contexto da interdisciplinaridade possibilita maior assimilação dos conteúdos, pois o aluno não está apenas recebendo e sim utilizando, aprimorando e contextualizando os conhecimentos que foram adquiridos. Tal como apontam Costa e Vieira (2018, p. 562) "o enfoque em atividades escolares colaborativas pode fomentar o desenvolvimento de níveis superiores da Taxonomia de Bloom - analisar, avaliar e criar -, uma vez que esses três exigem o pensar com o outro, a partir da interação de saberes múltiplos e diversificados.”

\section{Conclusão}

O objetivo desta pesquisa foi propor uma alternativa para o ensino de Biologia Celular no ensino médio a partir do uso de expressões artísticas e das metodologias ativas. Considera-se que a interdisciplinaridade, em especial no que diz respeito à 
associação de artes e biologia, pode trazer mais envolvimento e participação, em situações de aprendizagem no Ensino Médio. Tal fato foi inclusive registrado no diário de campo na presente pesquisa, seguindo de uma descrição da motivação apresentada com maior destaque na turma experimental do que na turma controle.

De modo geral, o uso das expressões artísticas para o aprendizado de Biologia Celular se mostrou eficaz, mas para que sua aplicação alcance êxito e demonstre resultados satisfatórios, é necessário que os alunos: i) interajam um nos outros e enxerguem a possibilidade de aprender também com os demais colegas; ii) enxerguem o professor como um mediador e/ou orientador do conhecimento de modo a garantir que o conteúdo seja abordado de forma correta; e iii) desprendam-se do modelo de sala de aula tradicional ou convencional, baseado em especial no modelo de aula expositiva, tomando as rédeas de sua aprendizagem. É preciso fazer com que os alunos se sintam parte do aprendizado e que sua colaboração é fundamental para que o esse processo aconteça de maneira eficaz.

Recomenda-se aos professores a aplicação das expressões artísticas de maneira interdisciplinar, assim um único trabalho elaborado pelos alunos será executado com mais tempo e sem sobrecarregá-los, de maneira a prover avaliações comuns computando notas para mais de uma componente curricular. Além disso, o um produto gerado obterá maior tempo de dedicação dos alunos em cada horário das componentes curriculares envolvidas na proposta interdisciplinar e contará com o acompanhado de especialistas em suas respectivas áreas de formação, de modo que, um professor que não tem um conhecimento aprofundado em alguma técnica ou área artística específica, poderá contar com o auxílio de outro professor que tenha esse conhecimento necessário. Recomenda-se também que os professores disponibilizem horários para atendimentos online, pois além de otimizar o tempo, o atendimento por meio de videoconferência permite aos participantes uma troca, em tempo real, de links ou imagens com ideias que forem surgindo ao decorrer do atendimento.

Como perspectivas futuras, pretende-se aplicar a proposta com estudantes do ensino fundamental de modo a verificar se os efeitos são similares aos dessa pesquisa. Além disso, pretende-se aplicar diferentes expressões artísticas em variados grupos de maneira a compará-las e verificar se alguma delas é mais eficaz para o ensino de Biologia Celular do que outra.

\section{Referências}

Adkins, S. J.; Rock, R. K. \& Morris, J. J. (2018). Interdisciplinary STEM Education Reform: Dishing out Art in a Microbiology Laboratory. FEMS Microbiology Letters, 365 (1), 1-8.

André, M. (2019). O que é um estudo de caso qualitativo em educação? Revista Da FAEEBA - Educação E Contemporaneidade, 22 (40), 95-103.

Araújo, L. F. S.; Dolina, J. V.; Petean, E.; Musquim, C. A.; Bellato, R. \& Lucietto, G. C. (2013). Diário de pesquisa e suas potencialidades na pesquisa qualitativa em saúde. Brazilian Journal of Health Research, 15 (3), 53-61.

Barros, M. D. M.; Zanella, P. G. \& Araújo-Jorge, T. C. (2013). A música pode ser uma estratégia para o ensino de ciências naturais? analisando concepções de professores da educação básica. Ensaio Pesquisa em Educação em Ciências, 15(1), 81-94.

Bastos, K. \& Faria, J. C. (2011). Aplicação de modelos didáticos para abordagem da célula animal e vegetal, um estudo de caso. ENCICLOPÉDIA BIOSFERA, 7 (13), 1867-1877.

Beaulieu, E. \& Petit-Turcotte, C. (2018), Gamification of learning in an introductory cell biology class. The FASEB Journal, 32: 535.35-535.35.

Cipolla, L. E. (2016). Aprendizagem baseada em projetos: a educação diferenciada para o século XXI. Tradução: Fernando de Siqueira Rodrigues, Porto Alegre: Penso, 2015. Escrito por William N. Bender. Administração: Ensino E Pesquisa, 17 (3), 567-585.

Berbel, N. A. N. (2011). As metodologias ativas e a promoção da autonomia de estudantes. Semina: Ciências Sociais e Humanas, 32 (1), 25-40.

Biagiotti, L. C. M. (2004). Avaliação em EAD: procedimentos de avaliação educacional em cursos de longa distância da marinha do Brasil. Dissertação de mestrado, Instituto Superior de Estudos Pedagógicos, Rio de Janeiro, RJ, Brasil.

BRASIL, Ministério da Educação (1998). Parâmetros Curriculares Nacionais: terceiro e quarto ciclos: Ciências Naturais. Brasília: MECSEF.

BRASIL, Ministério da Educação (2018). Base Nacional Comum Curricular. Secretaria Executiva, Secretaria de Educação Básica. Conselho Nacional de Educação. 
Cabral, E. M. C. (2009). A dialogia lúdica do professor de cursinho pré-vestibular: que diálogo é este? Dissertação de mestrado, Universidade Metodista de São Paulo, São Bernardo do Campo, SP, Brasil.

Cachapuz, A. F. (2014). Arte e ciência no ensino das ciências. Interaç̧̃es, 10 (31), 95-106.

Cavalcante, E. C. B. (2011). Cinema na cela de aula: o uso de filmes no Ensino de Biologia para a EJA prisional. 2011. Dissertação de mestrado, Universidade de Brasília, Brasília, DF, Brasil.

Colorado, H. A.; Mendoza, D. E. \& Valencia, F. L. (2021). A Combined Strategy of Additive Manufacturing to Support Multidisciplinary Education in Arts, Biology, and Engineering. J Sci Educ Technol 30, 58-73.

Correia, A. R. F. A. (2009). A Pedagogia em movimento: expressões artísticas para uma acção educativa inovadora. Dissertação de mestrado, Universidade da Madeira, Funchal, Portugal.

Costa, C. M. C. \& Vieira, A. A. S. (2018). Metodologias Ativas: a experiência do curso MAES. Revista Ibero-Americana de Estudos em Educação, 13 (esp1), 553-563.

Dalmoro, M. \& Vieira, K. (2013). Dilemas na construção de escalas Tipo Likert: o número de itens e a disposição influenciam nos resultados? Revista Gestão Organizacional, 6 (3), 161-174.

Demo, P. (2012). Pesquisa e informação qualitativa: aportes metodológicos. Papirus.

Duarte, S. G.; Martins, C. M. M. R.; Bandeira, L. G.; Carramillo, L. C.; Gervásio, M. P. \& Wanderley, M. D. (2018). Experiência interdisciplinar na educação básica e na formação de professores: artes, biologia e geociências. Terrae Didatica, 14 (3), 245-255.

Elias, M. A. \& Gorla, G. C. S. L. (2020). Experiência interdisciplinar no ensino de Biologia Celular e desenho arquitetônico. Scientia TEC, 7 (2), $130-143$. Gomes, F. D. R. \& Moura, F. N. S. (2020). A arte musical como metodologia ativa no ensino científico dos sistemas genitais. Experiência em ensino de ciências, $15(3), 442-454$

Guimarães, E. G.; Castro, L. S.; Bautz, R. K. \& Rocha, G. L. (2016). O uso de modelo didático como facilitador da aprendizagem significativa no ensino de Biologia Celular. Revista UNIVAP, 22 (40), 231.

Heinz, M. U.; Quintana, A. C. \& Cruz, A. P. C. (2019). Desenvolvimento cognitivo e afetivo dos estudantes de Contabilidade - influência do método de caso à luz da Taxonomia de Bloom. REPEC, 13 (4), 410-428.

Júnior, A. F. N. \& Souza, D. C. (2009). A confecção e apresentação de material didático-pedagógico na formação de professores de biologia: o que diz a produção escrita?. Enpec, Florinópolis, Santa Catarina, Brasil, 7.

Krathwohl, D. R. (2002). A revision of Bloom’s taxonomy: a overview. Theory in Practice, 41 (4), 212-218.

Liao C. (2016). From Interdisciplinary to Transdisciplinary: An Arts-Integrated Approach to STEAM Education, Art Education, 69 (6), $44-49$.

Lima, A. B. (2019). Tecnologia educacional no contexto do ensino de citologia: uso de aplicativo educacional na produção de um ambiente virtual de ensino e aprendizagem. Dissertação de mestrado profissional, Universidade de Brasília, Brasília, DF, Brasil.

Lopes, L. O.; Oliveira, P. R. P.; Santos, K. F.; Pomari, E. \& Thuler, D. (2019). O "maker" na escola: uma reflexão sobre tecnologia, criatividade e responsabilidade social. Congresso sobre tecnologias na educação, Recife, Pernambuco, Brasil, 4.

Machado, E. S. \& Júnior, G. G. (2019). Interdisciplinaridade na investigação dos princípios do STEM/STEAM education: definições, perspectivas, possibilidades e contribuições para o ensino de química. Scientia naturalis, 1 (2), 43-57.

Maeda, J. (2013). STEM + Art = STEAM. The STEAM Journal, 1 (1), Article 34, 1-3.

Marafigo, A. S. (2019). história em quadrinhos na sala de aula: um diálogo entre educação e arte. Trabalho de conclusão de curso, Universidade do Extremo Sul Catarinense, Crciúma, SC, Brasil.

Menegazzo, R. F. (2018). Teatro em biologia contribui para a aprendizagem e pode ser utilizado em outras disciplinas. South American Journal of Basic Education, Technical and Technological, 5 (2), 113-124.

Monteiro, C. M. S. (2015). A expressão artística como recurso didático e motivador no ensino-aprendizagem de uma língua estrangeira: estratégias para ensinar espanhol a estudantes da área de belas artes. Dissertação de mestrado, Universidade do Porto, Porto, Portugal.

Morin, V. L. \& Lüdke, E. (2019). Ensino de histologia e anatomia do aparelho reprodutor feminino através de metodologias ativas com alunas do ensino médio: um relato de experiência. Vivências, 16 (30), 15-29.

Pasqualetto, T. I.; Veit, E. A. \& Araujo, I. S. (2017). Aprendizagem Baseada em Projetos no Ensino de Física: uma Revisão da Literatura. Revista Brasileira de Pesquisa em Educação em Ciências, 17 (2), 551-577.

Olga, P. (2010). Epistemologia da interdisciplinaridade. Ideação, 10 (1), 9-40.

Prodanov, C. C. \& Freitas, E. C. (2013). Metodologia do trabalho científico: métodos e técnicas da pesquisa e do trabalho acadêmico. Novo Hamburgo.

Queiroz, I. R.; Mendes, N. F.; Galdino, D. A. A.; Amaral, J. H. S. \& Andrade, L. O. (2018). Metodologia mapas conceituais aplicada ao ensino superior: uma experiência com a disciplina de Biologia Celular. Revista EducaOnline, 12 (3), 69-87. 
Research, Society and Development, v. 10, n. 6, e26810615779, 2021

(CC BY 4.0) | ISSN 2525-3409 | DOI: http://dx.doi.org/10.33448/rsd-v10i6.15779

Santos, A.; Medeiros, F.; Paz, A.; Junior, J. R. \& Medeiros, R. (2019). Uso de projetos em salas de aula dos Institutos Federais: uma análise sob a ótica da Aprendizagem Baseada em Projetos e das competências do século 21. Revista Principia, 44, 113-121.

Santos, J. C. R.; Rocha, K. M.; Baroneza, A. M.; Fernandes, D. R.; Souza, V. V. \& Baroneza, J. E. (2017). Metodologias ativas e interdisciplinaridade na formação do nutricionista. Semina: Ciências Sociais e Humanas, 38 (1), 117-128.

Santos, R. O. B. \& Amorim, E. B. (2020). Metodologias ativas de ensino: taxonomia de Bloom e gamificação empregadas no ensino de engenharia. Revista de Ciências da Educação XXI, 46, 39-64.

Santos, R. S. S.; Gadelha, S. P. \& Bandeira, I. C. J. (2019). Concepção de discentes sobre a aplicação de metodologias dinâmicas na monitoria de genética e biologia molecular. Encontro de Extensão, Docência e Iniciação Científica, Quixadá, Ceará, Brasil.

Setúval, F. A. R. \& Bejarano, N. R. R. (2009). OS modelos didáticos com conteúdo de genética e a sua importância na formação inicial de professores para o ensino de ciências e biologia. Enpec, Florinópolis, Santa Catarina, Brasil, 7.

Silva, A. S. \& Fraga, N. M. (2017). A Arte aplicada ao ensino de Biologia: confecção de modelos didáticos de microrganismos. Educação Pública, 17 (11).

Silva, T. R.; Silva, B. R. \& Silva, B. M. P. (2018). Modelização didática como possibilidade de aprendizagem sobre divisão celular no ensino fundamental. Revista Thema, 15 (4), 1376-1386.

Silva, WM e Gobara, ST (2015). Teatro-Fórum: sequência didática e livreto para o ensino de biologia. Polyphonía, 26 (2), 527-541.

Silveira, J. R. A. (2018). Arte e Ciência: uma reconexão entre as áreas. Ciência e Cultura, 70 (2), 23-25.

Sousa, F. A. \& Coelho, M. N. (2020). As metodologias ativas como estratégias para desenvolver a interdisciplinaridade no ensino médio. DESAFIOS Revista Interdisciplinar da Universidade Federal do Tocantins, 7 (3), 42-55.

Sumida, S. S. \& Jefcoat, B. (2018). Anatomy, Animation, and Visual Effects: The Reciprocal Tools of Biology and Film-Making. Integrative and Comparative Biology, 58 (6), 1269-1278.

Túrmina, S. G. \& Rodrigues, M. G. (2016). Análise da efetividade da paródia enquanto estratégia didática no processo de ensinoaprendizagem da biologia a partir da percepção $\quad$ discente. Cadernos $\quad$ PDE, http://www.diaadiaeducacao.pr.gov.br/portals/cadernospde/pdebusca/producoes_pde/2016/2016_artigo_bio_unioeste_sandraghedinturmina.pdf

Vigario, A. F. \& Cicillini, G. A. (2019). Os saberes e a trama do ensino de Biologia Celular no nível médio. Ciência \& Educação (Bauru), 25 (1), $57-74$.

Volkweiss, A.; Mendes de Lima, V.; Ramos, M. G. \& Ferraro, J. L. S. (2019). Protagonismo e participação do estudante: desafios e possibilidades. Educação Por Escrito, 10(1), e29112.

Younas, A.; Pedersen, M. \& e Durante, A. (2016). Characteristics of joint displays illustrating data integration in mixed-methods nursing studies. International Journal of Advanced Nursing, 76 (2), 676-686.

Watson, A. D. (2015). Design Thinking for Life. Art Education, 68 (3), 12-18. 